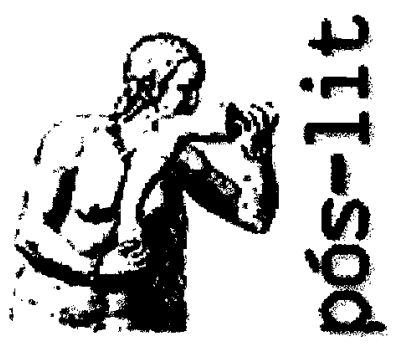

Programa de Pós-Graduação em Letras: Estudos Literários da Faculdade de Letras da UFMG

Artigo disponível em http://www.letras.ufmg.br/poslit

\section{O NARRADOR SEM AURA OU PENSANDO A REPRODUTIBILIDADE ORAL EM BENJAMIN}

Georg Otte $U F M G$

\section{ABSTRACT}

This is a study of Walter Benjamin's essay "The storyteller" starting from the concept of the aura, as it was developed by the same author in his essay "The Work of Art in the Age of its Mechanical Reproductibility". We try to show that the polarity between distance and nearness, which distinguishes the auratical work of art from the nonauratical, is also determinant for Benjamin's view of the oral story. 
Em seu ensaio "A obra de arte na era de sua reprodutibilidade técnica", Benjamin defende a tese de que a multiplicação da obra de arte moderna, como ela se tornou possível nas artes "técnicas" da fotografia e do cinema, causaria a destruição da aura. $\mathrm{Na}$ verdade, esta destruição não acontece, pois as novas artes não alteraram significativamente a recepção das artes tradicionais como a escultura e a pintura, que continuam produzindo suas obras até hoje. O que estava acontecendo na época em que Benjamin escrevia este ensaio era o surgimento de uma arte de massas, o cinema, cuja recepçăo foi marcada por uma espécie de "falta de respeito" diante da obra, pois essa massa "faz a obra de arte mergulhar em si"'. Surgia uma arte moderna e não-aurática ao lado das artes milenares e auráticas, sem que a primeira destruisse a aura das segundas. Não há indícios de que a recepção do cinema, apresentada por Benjamin como recepção democrática e participativa, tivesse alterado a recepçăo das obras de arte tradicionais, marcadas, como Benjamin diz, pela "autoridade da coisa".

Amenizando um pouco o ímpeto revolucionário de Benjamin, poderiamos dizer que a destruição não atinge tanto as obras de artes existentes, mas apenas o conceito de arte até então em vigor; poderíamos falar, mais modestamente, numa modificação do conceito de arte. Esta modéstia se impõe também pelo fato de o próprio cinema não ter escapado das armadilhas da aura, como mostra a existência dos cult-movies que, por mais reprodutíveis que sejam, adquiriram um "valor de culto". Hoje em dia, $6 \mathrm{O}$ anos depois de Benjamin ter redigido seu ensaio, o cinema já não é mais uma arte recém-nascida e parece que o simples passar do tempo é um dos responsáveis pela auratização de determinadas obras cinematográficas.

Cabe assinalar, também, que não é por acaso que Benjamin, quando fala das artes tradicionais e auráticas, se limita às artes plásticas, deixando de lado a música, o teatro e, sobretudo, a literatura ${ }^{3}$. Esta última, tecnicamente reprodutível desde Guthenberg, talvez seja a arte que mais questiona os pressupostos deste ensaio, pois destruir a aura de Goethe e de Machado de Assis, impedir uma postura de culto em relação a estes autores, é uma das tarefas de todo professor de literatura. Por mais que se

1. BENJAMIN, 1985. p. 193

2. 0p.cit. p. 168

3. Chamaremos músico e teatio, em analogio ou termo olemcio interpretierende Künste, de "ontes interpretotivos", pois o receppsāo

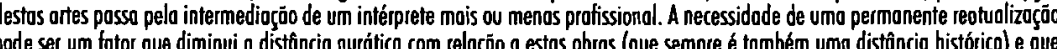

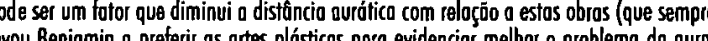

reproduza a obra dos autores clássicos, por mais que se aumente seu "valor de exposição", como Benjamin diria, a simples multiplicação técnica de seus livros não diminui o caráter aurático e muitas vezes autoritário destes autores; muito pelo contrário: o fato de se produzir um número muito grande da mesma obra normalmente contribui para realçar ainda mais sua singularidade. E, last but not least, o próprio Benjamin não escapou da ironia do destino de ser objeto de um verdadeiro culto e de carregar uma aura que, produto de uma veneração muitas vezes irrestrita, pode dificultar uma leitura crítica de suas obras.

O ensaio sobre a "reprodutibilidade técnica da obra de arte" não trata apenas de um novo conceito de produção, como seu título poderia sugerir. A reprodução técnica da mesma obra de arte através de um número infinito de cópias não é apenas uma questão de produção, mas se torna relevante por causa do, novo tipo de recepção que faz surgir 4 . Se a reprodutibilidade técnica da obra de arte é uma conseqüência um tanto inevitável da industrialização da produção artística, a recepção desta obra de arte industrializada abre perspectivas até então amplamente despercebidas. Apesar de uma série de afirmações duvidosas, é mérito de Benjamin ter detectado as novas dimensões das artes tecnicamente reprodutiveis graças a sua capacidade de observação em relação às mudanças do seu tempo. Benjamin viu que a revolução industrial da produção artística estava levando à revolução cultural de uma massificação da recepção, recepção esta que Benjamin acreditava constatar no próprio comportamento das pessoas.

Como já foi dito, o pivô desta revolução é a aura que envolve a obra de arte tradicional como uma espécie de couraça e que é responsável pelas dificuldades que as pessoas encontram em ter um acesso descomprometido a esta obra. Uma vez que Benjamin apresenta a reprodutibilidade como uma arma da técnica moderna contra o autoritarismo da obra de arte, a causa da aura que envolve estas obras deve ser procurada em sua singularidade. O protótipo desta obra singular seria a estátua grega, que, feita "a partir de um só bloco"5, serve como exemplo típico para o fato de a singularidade não ser apenas uma questão numérica, mas de ser antes de tudo a causa da distância entre ela e seu receptor. Para

4. Hó umo certo ambiguidade em relaçōo a termo do "reproduçōo": de moneiro quase imperceptivel, o termo, que inicialmente

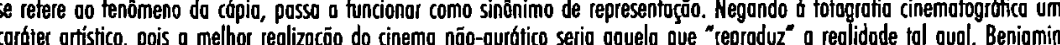

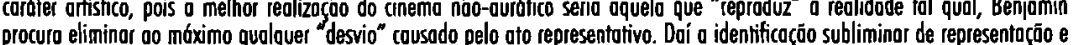

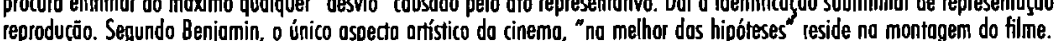
5. 0p.cit. p. 176. 
ilustrar o fenômeno da aura através da idéia do culto, Benjamin, de certo modo, inverte as coisas: de acordo com os pressupostos materialistas deste ensaio, não é o culto que exige a singularidade do seu objeto, mas é a própria singularidade do objeto que produz o culto.

Singularidade significa distância. Existe uma topografia da singularidade que faz com que apenas para uma minoria o objeto de culto seja disponível, sendo que a maioria se encontra numa distância permanente em relação a ele. Evidentemente, trata-se muito mais de uma topografia social que geográfica, reservando a um grupo de iniciados o acesso ao objeto sagrado. Sendo um objeto singular, o caso da obra de arte não difere essencialmente do objeto de culto religioso, incluindo-se a exclusividade do grupo dos iniciados como artistas e críticos de arte. A singularidade não apenas torna a obra de arte inacessível, mas parece evocar ao mesmo tempo o desejo de preencher o vazio da distância física através da criação de uma aura metafísica e de transformar a negatividade da distância numa virtude da obra. É esta a distância do culto, ou seja, a distância que não pode ser superada pela simples proximidade física, que Benjamin articula da seguinte maneira: "Em suma, o que é aura? É uma figura singular, composta de elementos espaciais e temporais: a aparição única de uma coisa distante, por mais perto que ela esteja."

Esta "definição", que ressalta os aspectos espaciais $e$ temporais da aura, aponta ao mesmo tempo para uma das incoerências do ensaio que justamente omite o fator tempo na formação da aura. A solução proposta por Benjamin, a reprodutibilidade técnica, tem um caráter puramente espacial. Sem dúvida, não havia ainda, no caso do cinema, uma distância temporal suficiente para se poder constatar que a multiplicação meramente física da obra cinematográfica não seria uma arma infalível contra a aura.

O ensaio sobre a reprodutibilidade da obra de arte acaba numa verdadeira apologia da proximidade. Proclamando o fim de uma aura distanciadora, Benjamin procura cumprir seu postulado de uma "politização da arte": a reprodução técnica da obra de arte, sua multiplicação industrial viria ao encontro de uma massificação também por parte dos receptores. É a própria massificação que apaga as divisas entre produção e recepção, levando a uma participação generalizada que não seria mais barrada por uma aura discriminadora. A reprodutibilidade técnica acabaria não só com o isolamento aurático da obra, mas também com sua recepção isolada e

6. Op.cit. p. 170 distanciada, chamada de "recolhimento" (Sammlung). A este recolhimento se opóem a "dispersão" e a "distração" - sinônimos do mesmo termo alemão Zerstreuung - marcando o começo de uma nova era, a era da reprodutibilidade técnica, onde homem e obra se integram. ${ }^{7}$

A reprodutibilidade da narrativa não é técnica, mas sim oral. Como Benjamin demonstra em "O narrador - Consideraçōes sobre a obra de Nikolai Leskov", as dicotomias do isolamento e da integração, da distância e da proximidade, que se evidenciam na comparação entre a obra aurática tradicional e a obra tecnicamente reprodutível também são relevantes para este outro ensaio antológico de Benjamin. A preocupação com a questão da distância se manifesta logo no início do ensaio, quando o autor apresenta o "narrador" Leskov:

Descrever um Leskov como narrador não significa trazê-lo mais perto de nós, e sim, pelo contrário, aumentar a distância que nos separa dele. Vistos de uma certa distância, os traços grandes e simples que caracterizam o narrador se destacam nele. Ou melhor, esses traços aparecem, como um rosto humano ou um corpo de animal aparecem num rochedo, para um observador localizado numa distâncio apropriada e num ângulo favorável. Uma experiência quase cotidiana nos impõe a exigência dessa distância e desse ângulo de observação. ... [grifo nosso]

Se no ensaio sobre o cinema, Benjamin ainda destacava as vantagens das novas técnicas do zoom e da câmera lenta, que permitem uma maior aproximação do objeto, ele agora fala sobre a "exigência" da distância. Os "traços grandes e simples" obrigam o observador a se distanciar do seu objeto para enxergá-lo em sua totalidade. Esta valorização inicial da distância se manifesta ainda quando o narrador é apresentado como "alguém que vem de longe". Benjamin poderia ter invertido o ditado popular "Quem viaja tem muito que contar" para "Quem conta tem que ter viajado", pois o interesse pela narrativa parece residir no fato de o

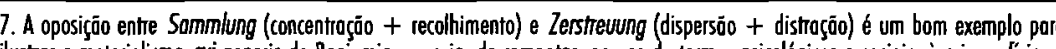
ilustrar o moteriolisma sui generis de Benjomin, ou seja, de remontar, no uso de fermos psicológicas e saciois, à arigem fisico

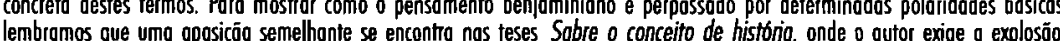

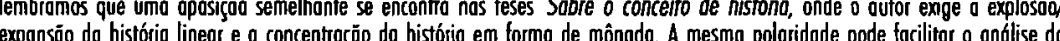
conceito benjaminiono do alegario.

8. Op. cit. p. 197

9. Op.cit. p. 198

10. Loc. cit. 
narrador ser alguém trazendo coisas de tempos e países distantes. Os dois "representantes arcaicos" do narrador, o camponês e o marinheiro," são viajantes no tempo e no espaço, cujas narrativas não despertam simplesmente o interesse do público por superarem grandes distâncias, mas também pelo fato de preservarem uma "aura" de distância ao serem contadas. Evidentemente, Benjamin não usa o termo "aura" em seu ensaio sobre a narrativa, mesmo que, neste ensaio, a distância não seja vista como um obstáculo, porém como um elemento psicológico que pode aumentar o fascínio pela narrativa. Considerando que a distância que separa a narrativa dos seus ouvintes pode ser superada pelo marinheiro e pelo camponês, ela tem muito mais o caráter de uma promessa do que de uma barreira.

As primeiras páginas deste ensaio sobre o narrador, publicado pouco depois do ensaio sobre a aura, ${ }^{12}$ parecem tomar um rumo contrário no que concerne à questão da distância. Entender Leskov e entender o fascínio pelas suas narrativas implica em aceitar a necessidade de um certo distanciamento, ou, mais exatamente, a necessidade de um jogo paradoxal entre distanciamento e aproximação. Por um lado, o camponês e o marinheiro superam distâncias no tempo e no espaço, mas, por outro, aproximam dos seus ouvintes algo que, na verdade, não perdeu a aura dos países e dos tempos distantes. $\mathrm{O}$ interesse pela narrativa, portanto, não é simplesmente um interesse pelo desconhecido, mas sempre se alimenta da certeza concomitante de esta distância ser superável. As experiências alheias dos tempos antigos e dos lugares longínquos não fascinam apenas pelo fato de serem estranhos, mas também pela certeza de estas experiências poderem ser inseridas na "experiência" própria, ou seja, pela certeza de trazerem consigo alguma coisa já conhecida, uma chave que permite que o mundo próprio se abra à experiência alheia.

No entanto, Benjamin não prossegue, no decorrer do ensaio, na valorizaçẫo da distância enquanto elemento constitutivo para a recepção da narrativa e passa a se concentrar no seu efeito aproximador. Ele também não prossegue, aliás, nas "considerações" sobre Leskov, esse narrador que "está à vontade tanto na distância espacial como na distância temporal" ${ }^{13} \mathrm{O}$ narrador projetado nas páginas seguintes não é nenhuma figura de destaque que deixa seus escritos como herança para a posterioridade, mas é o

11. Op.cit., p. 199

12. De acordo com o cronologio de suas obras, Benjomin deve ter trobah hoda durante algum tempo (inicio de 1936), simultoneamente nos dois ensoios.

13. Op.cit. p. 199; o hábito benjominiona de "nõa folor do assunto", ou sejo, de nāo trator de um determinado ossunto nos moldes do discuro ocadêmico, mas sevvindo-se de um procedimento ensóstico, merecerio umo análise próprio. narrador ad-hoc, pois qualquer membro de uma comunidade pode se transformar de ouvinte em narrador. Talvez seja para evitar um tratamento aurático da pessoa de Leskov, que Benjamin evita falar de um autor específico e singular do século XIX para passar a fazer considerações gerais sobre um narrador anônimo, vagamente localizado num âmbito medieval ou pós-medieval. Uma vez que os conceitos da originalidade e da autoria eram estranhos ao pensamento medieval, esta época se oferecia a Benjamin como ambiente ideal para desenvolver sua idéia de uma narrativa enquanto bem coletivo de uma comunidade.

Uma das características que marcam a transição da Idade Média para o Renascimento é justamente a tendência desta última época a procurar as origens das coisas e de localizar esta origem na figura de algum autor. $\mathrm{O}$ lema do Renascimento, ad fontes, marca o início de um pensamento que historiciza e, conseqüentemente, individualiza principalmente a produção artística no afã de proporcionar-lhe uma identidade. Acontece que esta busca da identidade muitas vezes acabava numa mistificação das origens distantes, transformando a singularidade da autoria na aura da obra e de seu autor.

A mudança do individual para o coletivo, no entanto, não se refere apenas à questão da individualidade de um narrador como Leskov. Além da substituição do marinheiro e do camponês pela comunidade artesanal, aconteće também uma mudança quase imperceptível quanto à questão da recepção. Não se trata mais da relação entre indivíduo e narrativa, onde a distância ainda era responsável por um certo "suspense", desempenhando uma função psicológica e estética. Se o próprio marinheiro ainda trazia consigo um sabor de exotismo, ou melhor, a aura do exotismo de suas narrativas, a narrativa do meio artesanal não carrega mais a marca da distância. Sendo uma obra 'oralmente reprodutível' e sendo independente de qualquer base material a não ser a voz do narrador, a narrativa não tem como formar uma aura em torno de si, criando barreiras que a separem dos seus ouvintes. A relação entre narrador e ouvinte é "ingênua", ou seja, a própria distinção entre narrador e ouvinte se torna irrelevante:

Não se percebeu devidamente até agora que a relação ingênua entre o ouvinte e o narrador é dominada pelo interesse em conservar o que foi narrado. Para o ouvinte imparcial, o importante é assegurar a possibilidade da reprodução [Wiedergabe]. ${ }^{14}$

14. Op.cit. p. 210 
"Assegurar a possibilidade da reprodução" é como assegurar a continuidade da produção (e reprodução) artesanal, que não apenas garante a existência de cada um, mas também sua integração nesta comunidade. $O$ "interesse em conservar o que foi narrado" é completamente diferente dos esforços enormes que se fazem para conservar as obras do passado em grandes museus nacionais, onde os visitantes admiram respeitosamente os produtos dos grandes artistas, sempre observando a proibição de não tocar as obras e respeitando a devida distância. A narrativa não é intocável muito pelo contrário: cada membro da comunidade artesanal tem que se apoderar dela para garantir sua conservação.

As origens da narrativa sendo desconhecidas, é como se ela tivesse brotado naturalmente do espírito de algum grupo de artesãos e seu ritmo regular de trabalho. Se é que podemos atribuir alguma origem à narrativa, é a origem enquanto Ursprung que Benjamin define no prefácio de Origem do drama barroco alemão:

O termo origem não designa o vir-a-ser daquilo que se origina, e sim algo que emerge do vir-a-ser e da extinção. ${ }^{15}$ [no original alemão: "Im Ursprung wird kein Werden des Entsprungenen, vielmehr dem Werden und Vergehen Entspringendes gemeint." $]^{16}$

No momento em que os ouvintes se distanciarem da narrativa oral, momento em que a narrativa se tornar intocável devido a uma aura distanciadora, ela deixa de existir. "Assegurar a possibilidade da reprodução", assegurar a reprodutibilidade oral, é uma necessidade vital para a narrativa, que, ao contrário das obras plásticas, simplesmente não existe sem esta reprodução. A escultura e a pintura, uma vez produzidas por algum artista, passam a existir por elas mesmas, dispensando não apenas a reprodução ou a participação das outras pessoas, mas, como Benjamin mostrou, isolando-se destas pessoas devido a sua aura. $O$ fato de a narrativa não existir enquanto objeto material faz com que seus participantes, de certo modo, sejam obrigados a se apropriarem da narrativa para conservála.

A idéia da integração, que passa a prevalecer na segunda metade do ensaio, ainda é reforçada quando Benjamin fala da comunicação

\section{BENJAMIN, 1984. p. 67.}

16. BENJAMIN, 1980. Vol.I, p. 210; 0 original olemōo evidencia como Benjomin remotivo Ursprung como derivado de Sprung/ springen = salto/ saltor, jogando, mois umo vez, com o sentido conceto de um elemento lexical. Deste modo, o Ursprung da norrotivo nâo e suo origem, que poderio ser locol "artesanal":

A narrativa, que durante tanto tempo floresceu num meio de artesãos - no campo, no mar e na cidade -, é ela própria, num certo sentido, uma forma artesanal de comunicação. Ela não está interessada em transmitir o "puro em-si" da coisa narrada como uma informação ou um relatório.

Ao contrário da informação de imprensa ou do relatório, a narrativa não é um discurso sobre alguma coisa, não é sua função veicular alguma notícia. Seguindo suas reflexões reunidas em Sobre a linguagem em geral e sobre a linguagem do Homem, ${ }^{17}$ onde Benjamin condena o uso da linguagem enquanto simples meio de comunicação, ele nega à narrativa, enquanto obra de linguagem, uma função puramente comunicativa. A narrativa é parte de uma "experiência" que pode ser "incorporada" à experiência coletiva, como o marceneiro incorpora uma peça no todo do seu objeto artesanal. O hábito dos narradores começarem "sua história com uma descrição das circunstâncias em que foram informados dos fatos que vão contar", ${ }^{18}$ faz parte da prática "artesanal" de considerar esta história como parte de uma totalidade maior. É esta facilidade de "incorporação" ou de integração que impede um tratamento distanciado da narrativa e o surgimento de uma aura distanciadora.

Paradoxalmente, as circunstâncias enquanto marcas diferenciadoras e distanciadoras conferem ao mesmo tempo verossimilhança à narrativa, pois é através destas circunstâncias, fictícias ou não, que o narrador pode apresentar a narrativa como algo "incorporado" em sua vida e como algo "incorporável" na vida de seus ouvintes. Estas circunstâncias fazem com que a narrativa seja considerada como "peça" de uma determinada realidade, são os vestígios materiais que 'comprovam' que a narrativa surge diretamente da "matéria da vida vivida" se trata do produto de uma mente solitária como no caso do romance. No contexto da narrativa "artesanal", o romance aparece como gênero da desintegração da era industrial, sendo que a isolamento se apresenta em todos os níveis, ou seja, na solidão do autor, do protagonista e do leitor. Apoiando-se explicitamente na Teoria do Romance de Lukács e na idéia do "indivíduo desabrigado" deste último, Benjamin projeta o romance como antípoda da narrativa integradora.

17. BENJAMIN, 1980. Vol. II, p. 140-157.

18. BENJAMIN, 1985. p. 205.

19. BENJAMIN, 1980. Vol. II, p. 442. 
Nada impede, aliás, que as circunstâncias em que o narrador integra sua narrativa sejam invenção; ao contrário da informação de imprensa, que se limita a relatar fatos verificáveis da realidade externa, a força de conviç̧ão da narrativa não reside na veracidade dos fatos narrados. A verdade da narrativa é de outra natureza e depende muito mais da questão se a narrativa, enquanto 'peça', se encaixa ou não na experiência coletiva. Platonicamente falando, a narrativa, como qualquer ficção, é um "simulacro" da verdade, uma representação "mal feita" de uma realidade que, por sua vez, já é um simulacro defeituoso da Idéia. A narrativa, enquanto simulacro do simulacro, é uma "mentira"; o segredo de uma boa mentira, no entanto, está no fato de haver "circunstâncias" que a vinculem à "experiência" e que a tornem verdadeira enquanto representação bem-sucedida desta experiência. O sucesso da narrativa não depende da questão do certo e do errado, ou do fato dela estar em acordo com a Idéia enquanto origem da verdade, mas depende da sua qualidade estética, ou seja, da questão de poder ser incorporada numa totalidade que Benjamin prefere chamar de "experiência". ${ }^{20}$

A própria narrativa traz consigo as circunstâncias em que foi contada, deixando claro que a "coisa narrada" não é um fato isolado, mas um fato integrado numa determinada experiência humana. A narrativa

mergulha a coisa na vida do narrador para em seguida retirá-la dele. Assim se imprime na narrativa a marca do narrador, como a māo do oleiro na argila do vaso. ${ }^{2}$

A "marca do narrador", portanto, é a marca da integração da "coisa narrada" em seu ambiente humano, é o vestígio [Spur ${ }^{22}$ que aponta para o contato direto entre os narradores-artesãos e sua obra. Este vestígio é como uma prova de que a narrativa não escapou das mãos dos envolvidos, que ela não formou uma aura tornando-se intocável.

Numa carta de 9/12/1938 a Adorno, Benjamin escreve: "O conceito do vestígio encontra sua determinação filosófica em oposição ao conceito da aura." 23 A observação faz parte da discussão em torno do

20. Paro o relaç̃o entre o Verdode e o Belo, đf. BENJAMIN, 1984. p.52-53: "Nele [no Simpósio de Plotão] o Verdode é opresentododa como o conteúdo essencial do Belo, a reino dos idéios, e o verdade é considerado belo. A compreensóno dessas teses plotônicos

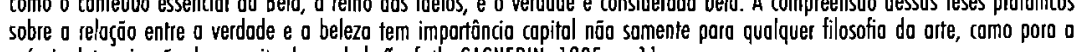

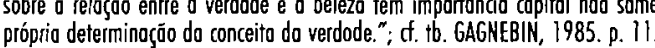

21. BENJAMIN, 1985. p. 205

22. BENJAMIN, 1980. Vol.1I, p. 447

23. BENJAMIN, 1978. p. 792. primeiro ensaio de Benjamin sobre Baudelaire (Charles Baudelaire. Um lírico no auge do capitalismo), cuja publicação Adorno recusou em nome do "Instituto". Os dois leitmotive ${ }^{24} \mathrm{da}$ "aura" e do "vestígio", no entanto aparecem nos mais diversos textos de Benjamin, e mesmo que confrontação direta dos dois termos, como nesta carta, seja uma exceção, trata-se dos dois pólos de uma dicotomia que pode ser associada à dicotomia entre a idéia da integração e a do isolamento. Os "vestígios" são os nexos materiais que vinculam a experiência individual à experiência coletiva e conseqüentemente, são responsáveis pela integração do particular no seu contexto maior, ao contrário da aura que isola o particular do contexto de um determinado presente.

A "mão do oleiro", no entanto, aponta ainda para outro fenômeno que Benjamin chama de "perfectibilidade" ${ }^{25}$ [Verbesserungsfähigkeit] $]^{26}$ e que diz respeito à possibilidade de se manipular a obra ou, pensando na "mão do oleiro", de manusear a obra à vontade. Voltando ao âmbito do cinema, isto significa que não existe uma versão definitiva de um filme, pois este, sendo o produto de uma montagem que aproveita apenas uma pequena parte do material filmado, pode ser alterado a qualquer hora. Opondo o filme à estátua grega, Benjamin acredita ver no primeiro a chance revolucionária de se ter uma obra aberta apenas pelas suas condições técnicas. Hoje sabemos que esta manipulação, por vários motivos, não acontece. Ao contrário da tese do terceiro capítulo, a obra reprodutível não escapa da questão da autenticidade; apesar de tecnicamente possível, a reatualização da obra cinematográfica através de uma nova montagem não acontece. Ao contrário do material das filmagens, a argila do oleiro é modelada ao gosto pelo artesão, ou seja, cada narrativa, desde que seja uma narrativa oral, carrega os vestígios das "mãos" de seu narrador.

Portanto, o "vestígio da mão do oleiro na argila do vaso"z7 não aponta apenas para a inserção da narrativa na "vida vivida", mas também para o caráter imediato (não-mediado) desta inserção. Da mesma maneira que o vaso toma forma na mão do oleiro, o "manuseio" permanente da

24. Damos preferênncio ou termo olemōo - internacionalmente adotodo - do leitmotiv ("motivo condutar"), o0 invés de folor en "conceito", termo usodo pelo próprio Benjomin nesto corto, parém ossaciado oo pensomento téárico. É curioso que o próprio termo Spur, traduzidos nos diversos textos por "marco", "vestígio", "pisto", etc. é um destes leitmotive dentro do obra de Benjumin, ou seja, um vestígio que conedo textos e contextos aporentemente distontes. A varioşoo bem-intencionodo no troduşão do mesmo vestigios na interior do obro benjominiono.

25. BENJAMIN, 1985. p. 175

26. BENIAMIN, 1980. Vol.II, p. 446

27. BENJAMIN, 1980. Vol.II, p. 447 
narrativa pela comunidade 'artesanal' aponta para um contato direto, que Benjamin, no ensaio sobre a obra de arte, já havia postulado para o cinema e a arquitetura. Do mesmo modo que as obras cinematográficas e arquitetônicas podem ter um caráter "tátil", o contato diário com a narrativa evita a formação de uma aura distanciadora entre ela e seus usuários. Fazendo uso permanente da narrativa, o narrador e seus ouvintes confirmam a validade da "experiência" da qual foi "retirada". Evidentemente, nos tempos do cinema, esta experiência, enquanto fundamento universal, já não existe mais; não há mais os vestígios que poderiam "inserir" [einbetten] a obra de cinema numa totalidade maior.

A relação entre oralidade e uso, assim como entre oralidade e artesanato, já foi objeto de um dos diálogos de Platão. ${ }^{28}$ No final do diálogo Fedro, a defesa da oralidade é explícita, pois, segundo Platão, é apenas ela que garante a mediação bem-sucedida de um saber que não consiste no conhecimento dos textos, mas na habilidade "artesanal" de reagir conhecimento dos textos, mas determinada situação. A palavra escrita, por ser anteriormente fixada, não acompanha a mudança permanente das situaçóes, de modo que qualquer escrita que perpasse as mudanças do tempo sofre um processo de isolamento. Conseqüentemente, o conhecimento destes textos "defasados" faz parte de um saber que é reservado a um grupo de conhecedores e que, uma vez que não se adapta às necessidades do presente, apresenta todas as características da mentalidade aurática. Para ilustrar suas reflexões, Platão não apenas recorre, como Benjamin, a comparaçóes com o artesanato, mas radicaliza ainda mais o aspecto do uso prático: não é quem faz a sela que decide se ela é boa, mas o cavaleiro. ${ }^{29}$

O paralelo entre as reflexóes de Benjamin e o Fedro, no entanto, vai além de uma coincidência no emprego das metáforas, pois a oposição entre a palavra oral e a palavra escrita aponta novamente para a questão da "perfectibilidade" ou alterabilidade da obra. A palavra escrita, por ser um testemunho fixo do passado que sobrevive ao passar do tempo, constitui uma realidade alheia à situação do presente. $O$ "choque" entre o texto do passado e o contexto do presente poderia ser superado ou, pelo menos, amenizado através da aquisição de conhecimentos sobre esta obra, que a integrariam no novo contexto.

No caso da narrativa oral, a questão do uso prático simplesmente

28. Os seguintes comentários sobre Plotōo se opoiam em WIELAND, 1987. Wielond chama a otenģão para o fato de a próprio forma do dílogo plotônico ser um indício do prefeerêncio de Platão pelos formas orois.

29. WIELAND, op. cit. p. 29 não se coloca, pois oralidade significa uso, ou seja, a narrativa não tem como continuar existindo sem ser "usada". O fato de a narrativa não ser materialmente fixada e de o narrador poder deixar nela suas "marcas", que são as marcas do momento, faz com que ela, mesmo sendo representação de determinadas constantes antropológicas, passe por um processo permanente de reatualização. Se a narrativa é "expressão" de um "passado coletivo", o fato dela passar de pessoa a pessoa nos termos do "uso artesanal" lhe confere um dinamismo que impede que ela caia em "desuso", como a obra de arte plástica. É este dinamismo que faz com que os dados inconscientes, guardados numa memória coletiva, mantenham os nexos com a "superfície" do presente. Não sendo materialmente fixada, a narrativa não pode se tornar autônoma e se afastar do contexto de um determinado presente ou se chocar com ele.

Enquanto o romance, na qualidade de texto flxo, é suscetível a formar uma barreira aurática devido à diferença histórica entre sua criação e sua atualização pelo leitor, a narrativa se assemelha mais às artes interpretativas pela necessidade de ser constantemente recriada por alguém. O narrador compartilha com o ator e o músico a função de servir de mediador entre uma criação que "vem de longe", ${ }^{30}$ ou seja, de tempos e lugares distantes. No entanto, o fato de cada ouvinte poder se tornar narrador, de a recepção e a produção poderem se unir na mesma pessoa, coloca a narrativa ainda numa posição particular, também em relação às artes interpretativas: embora o intérprete possa diminuir o caráter aurático da criação original, embora ele possa "fazer uso" desta obra dentro de uma certa margem de liberdade interpretativa, sua interpretação pode passar por um processo de consagração, ${ }^{31}$ tornar-se aurática e dificultar o "manuseio" descomprometido nas interpretações posteriores.

Os dois ensaios sobre o cinema e a narrativa, apesar das diferenças aparentes, evidenciam que Benjamin se deixou guiar por uma mesma preocupação, que é a apropriação da obra pelo seu receptor. Se a aposta benjamiana no progresso técnico e no automatismo deste progresso deixa uma série de dúvidas, a volta para o narrador medieval parece resolver melhor a questão desta apropriação. A narrativa também é reprodutível Não se trata, no entanto, da reprodução técnica, ou seja, da cópia sempre igual da mesma obra, mas de uma reprodução "artesanal" que, apesar de se tratar sempre da mesma narrativa, absorve os "vestígios" das "mãos" de

30. BENIAMIN, 1985, p. 198

31. Observe-se que o próprio termo "consoggraçāo" oponta para o ômbito religioso, para o culto a sagrado. 
cada narrador. É justamente a "mesmice" da obra cinematográfica que a aproxima da inalterável estátua grega, pois os freqüentadores de cinema não têm como "por a mão" na obra. Se a distância com relação à obra cinematográfica cresce cada vez mais, deixando espaço para a formação da aura, a narrativa, enquanto obra oralmente reprodutível, possibilita a reatualização do passado no presente.
REFERÊNCIAS BIBLIOGRÁFICAS

BENJAMIN, Wolter: Briefe [Cortos]. Edicōo e notos: Gershom Scholem, Theodor W. Adorno. Fronkfurt a. M.: Suhrkomp, 1978 BENJAMIN, Wolter: Gesammelte Schriften. Vols. I-VI. Frankfurt: Suhrkamp Verlog, 1980.

BENSAMIN, Wolter: Origem do dramo barroco alemōo. Froduşōo, opresentoģōo e notos: Sérgio Paulo Rouanet. Sõo Poulo: Brosiliense, 1984 . Wolter: Obras escoltida
Brosiliense, 1985 .

GAGNEBIN, Jeonne-Mricie: Wolter Benjomin e o histório oberto [Prefócio do Vol. I dos Obros escollhidos de W.B.].

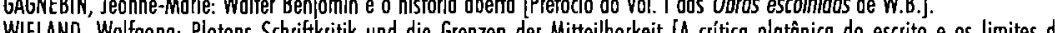

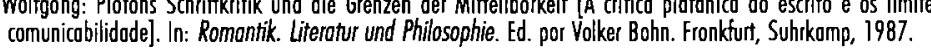

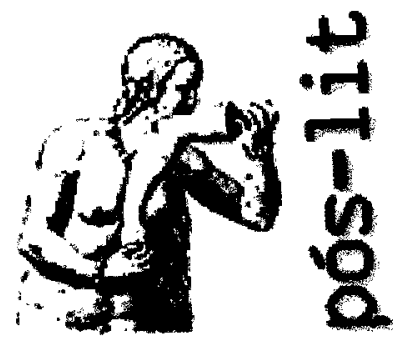

Programa de Pós-Graduação em Letras: Estudos Literários da Faculdade de Letras da UFMG

Artigo disponível em http://www.letras.ufmg.br/poslit 